\title{
Antoine Berman, tradutor de Augusto Roa Bastos
}

Adalberto Müller*

\section{I- Ética e política do traduzir: Berman e Roa Bastos}

No Brasil, as ideias de invenção e de criação em matéria de tradução - senão em matéria literária - estão frequentemente associadas à poesia, e quando muito, a romances experimentais escritos por poetas. Não será de todo improvável que essas noções tenham se formado a partir das ideias românticas de gênio e de originalidade, que assumiram no modernismo a forma da produção de novidade. As regras são bastante conhecidas e foram bem delineadas em 1924 no Manifesto da Pau-Brasil de Oswald de Andrade:

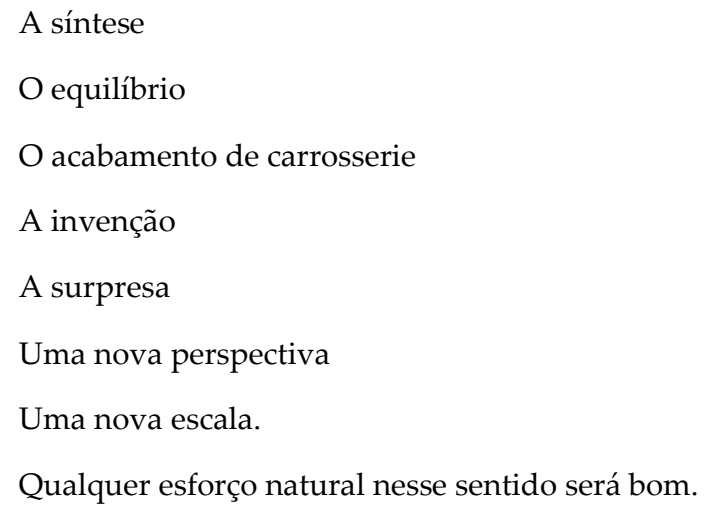

${ }^{*}$ Universidade Federal Fluminense 
Retomadas pelos poetas do concretismo, as ideias de originalidade e de invenção chegaram ao paroxismo com o lema poundiano do "make it new". Não se tratava, porém, de um fazer ex nihilo, mas de tornar novo o já feito. Assim, a ideia de "transcriação", que Haroldo de Campos foi buscar tanto em Ezra Pound quanto na Umdichtung benjaminiana (de matrizes românticas, aliás), passa a marcar fortemente uma tendência mais criativa na prática e na teoria da tradução no Brasil - tanto quanto a ideia de "invenção" dos concretos criou raízes em nossa poesia.

Em contraponto ao pensamento transcriativo dos concretos, a difusão das ideias de Antoine Berman, no campo teórico e prático da tradução literária, deslocou o sentido do debate, relativizando a orientação para a originalidade estética (o efeito de estranhamento produzido na forma do texto), e aproximando-o de uma ética da diferença. Segundo essa ética, a relação com o estrangeiro, com o Outro (entendido no sentido antropológico e psicanalítico), pode ser mais "etnocêntrica" ou mais "ética" (relacional, dialógica) ou "literal" (apegada à materialidade, ao significante lacaniano), e isso produzirá efeitos no texto traduzido: "domesticação" ou "estrangeirização", conforme a terminologia que Lawrence Venutti (1998) criaria a partir de Berman.

Mais recentemente, Barbara Godard atentaria para o fato de que a teoria de Berman é bem mais do que uma analítica descritiva do traduzir: é antes o anúncio de uma virada ética, na qual a tradução opera como uma forma de arqueologia foucaultiana ou uma gramatologia derridiana, e fundamenta um saber capaz de expandir-se para além das questões meramente textuais. Para Godard, o pensamento ético sobre o traduzir que se segue a Berman (p. ex., VENUTI 1998, SPIVAK, 1993) deriva de suas formulações, e ao mesmo tempo expande o seu horizonte textualizante, o seu "formalismo abstrato" em direção a uma politização da diferença, na qual se desenham mais claramente relações de poder:

Dans la conceptualisation de Berman, cependant, l'interculturel reste un formalisme abstrait et n'aboutit pas à une véritable compréhension de la différence culturelle, telle que Venuti ou Spivak l'envisagent, la traduction ayant une tâche différencialisante. Pour eux, la visée éthique s'adresse à des rapports de hiérarchie entre des langues et des cultures: par le biais d'un 


\begin{abstract}
effort pour les transformer en reconnaissance réciproque, l'éthique se situe sur le terrain de la politique. La traduction a des effets à la fois sur la langue et la culture d'origine et sur la langue et la culture d'arrivée. Pour Berman, la visée éthique en tant que réflexivité critique est un mode d'autoconnaissance. Comme travail de l'esprit, la traduction critique facilite l'éloignement du langage naturel et ainsi contribue à l'innovation culturelle. Ce nouvel éclairage manifeste la langue potentielle dans l'unité de sa plénitude à venir. Pour Berman, la traduction fait advenir un français potentiellement autre. Pour Venuti et Spivak, comme pour moi-même, la traduction élargit la compréhension d'une langue et d'une culture autre que la langue natale. (GODARD, 2001, p. 77-78)
\end{abstract}

Não vou discutir aqui se Barbara Godard tem razão em deixar o teórico Antoine Berman na margem de uma fronteira que ele teria desbravado antes, e que teóricos posteriores teriam ultrapassado. Quero antes demonstrar, na análise mais detida de uma tradução de Antoine Berman (Moi le Suprême, de Augusto Roa Bastos), que as dimensões política e ética entram em confluência com as questões estéticas, de modo que a invenção (textual) aparece novamente em pauta, só que agora a poesia da tradução se concilia com uma dimensão ética e política, na qual o convívio e a diplomacia passam a ser fatores importantes. Será preciso, pois, acompanhar o fluir do texto de Berman com o de Roa Bastos como se acompanha a confluência de dois rios (sejam o Paraguai e o Paraná, ou o Ródano e o Saône), formando uma "terceira margem".

Como se verá, minha leitura da tradução de Berman entra em franca discordância com aquela leitura proposta por Charron (2001) na sua análise aleatória das páginas iniciais da tradução de Yo el Supremo, que tinha por objetivo demonstrar "la nature du fossé qui existe chez Antoine Berman, entre la pratique du traducteur et le discours" (CHARRON, 2001, p. 120), como se lê desde o resumo do artigo. Ora, parece-nos que a leitura taxonômica e baseada, conforme o autor mesmo admite, na escolha de extratos aleatórios da tradução de Berman acaba por atribuir defeitos pars pro toto ao trabalho do tradutor, deixando de compreender o modo como a tradução de Berman se situa num panorama mais amplo de interpretação do romance de Roa Bastos dentro de um momento histórico e cultural da América Latina. Por isso mesmo, convém situar o projeto da tradução de 
Berman na sua incursão crítica no terreno latino-americano, tal como propõe Simone Petry (2016), que entendeu tal incursão como uma "poiesis da convivência". Além do mais, convém também delinear um panorama de leitura mais amplo do romance de Roa Bastos, de modo que a análise esteja contextualizada tanto por uma leitura crítica do original quanto por uma leitura da ética do tradutor.

No que diz respeito ao projeto inicial de Berman, há uma convergência entre o pensamento da "convivência", desenvolvido por ele no período em que viveu na Argentina, e a significação do romance de Roa Bastos, se pensarmos esse romance como um protótipo de um pensamento latino-americano, tal como formulado por Berman em seus textos sobre a América Latina (BERMAN, 1980, 1982), os quais dialogam com o texto escrito com sua companheira Isabelle Garma (1976) e com o ensaio “Maté et communication" (1975). Se assim for, a leitura da tradução de Yo el Supremo pode ser uma chave para se entender a formulação inicial das ideias de Berman sobre a tradução, especialmente no que diz respeito às questões éticas, formulação que terá impacto na obra tradutológica mais conhecida de Berman.

Seguindo os passos de Petry (2016, p. 112 ss.), os anos de vida de Berman e Isabelle Garma na Argentina foram marcados por um período de efervescência do peronismo, que terminaria tragicamente com o golpe militar de 1976. No centro do debate peronista estava a rediscussão do papel da classe trabalhadora e dos marginalizados na partilha do poder e da cultura. Nesse sentido, para o crítico Berman, a discussão de uma literatura latino-americana engajada com problemas sociais e históricos iria ao encontro de uma parlance (falância), de uma oralidade, de uma expressão dos grupos minoritários: indígenas, camponeses, suburbanos. No texto "La voix des sans voix", a propósito de José Maria Arguedas (Peru), Manuel Scorza (Peru), Roberto Arlt (Argentina) e Augusto Roa Bastos (Paraguai) - mas também sobre João Guimarães Rosa - Antoine Berman postula a ideia de uma literatura que não apenas integra os grupos marginalizados e os pobres, mas incorpora a oralidade dos falares regionais (incluindo-se aí as línguas indígenas e dialetais, como o lunfardo). Paralelamente, segundo uma tendência histórica na América hispânica, tais autores tensionam a relação 
entre ficção e história, invenção e testemunho, criando obras híbridas como Yo el Supremo, cujo valor extraordinário Berman assim sintetiza (e o leitor pensará certamente nos desdobramentos dessa síntese para a leitura subsequente que Berman faz do romantismo alemão):

\begin{abstract}
Em um nível mais profundo, a obra se torna uma reflexão sobre fala e escrita, história e política, poder, tempo e morte, dimensão através da qual a obra se afirma simultaneamente como literatura, reescrita da história, ensaio, crítica e teoria, características bem "modernas" que fariam dela uma obra europeia, se não estivesse solidamente enxertada [entée] no universo oral/mítico latino-americano. (BERMAN, 1980, p. 5)
\end{abstract}

Essa metáfora vegetal da enxertia (que, no francês, remete inclusive a questões etimológicas/culturais entre enture e greffage) aponta para o caráter de artifício, de construção cultural (de tradução, diríamos), em oposição a uma visão da literatura colonial como uma planta que cresce naturalmente e se ramifica em solo estrangeiro. Impossível não lembrar aqui da imagem de Antonio Candido sobre o momento de formação da literatura brasileira: "A nossa literatura é galho secundário da portuguesa, por sua vez arbusto de segunda ordem no jardim das Musas". Mas o que realmente importa é salientar que esse caráter polimórfico do texto roabastiano está enxertado num tronco "arcaico" onde as ideias de oralidade, de convívio e de comunicação já estão solidificadas. Essa ideia também se desenvolve num outro texto de implicação vegetal, "Maté et communication"1, texto que, como demonstra Petry (2016), também terá forte impacto sobre a concepção ética de Berman da tradução como forma de convívio com o estrangeiro.

As considerações de Berman sobre a "falância" são importantes para entender o romance de Roa Bastos. Publicado em 1974 em Buenos Aires (quando Berman lá se encontrava), Yo el Supremo parte de uma tentativa de reconstrução histórica e biográfica do governo do ditador ilustrado Gaspar Rodrigues de Francia, desde os anos da indepêndencia do Paraguai (1811) até o final de seu longo governo, que termina com sua morte em 1840. Nem

\footnotetext{
${ }^{1}$ Vale lembrar que nesse texto Berman - intencionalmente ou não - desconsidera a tradição ritual do uso do mate entre os povos do tronco tupi-guarani do Cone Sul.
} 
pura história, nem pura ficção, Yo el Supremo é um romance bífido², em que a figura do autor e a do personagem histórico se fundem, na esquina de um tempo conjectural, para formar uma narrativa que oscila entre a primeira pessoa fictícia e a pessoa "real" do personagem histórico, formando um YO que é como uma suprema ficção (uma super-ficcção, que não se confunde com a onda atual de autoficção). Esse caráter ambíguo (para um ficcionista) e incongruente (para um historiador) cria um sistema narrativo sem par, que permite a Roa Bastos atravessar as paredes do tempo histórico, criando uma quarta dimensão da realidade, em que o presente de uma ditadura sanguinária e injusta (a de Stroessner) se cruza com uma outra "ditadura", que pode ser sido cruel (já que era fruto de uma revolução, como a de Bonaparte) mas que criou na América Latina uma primeira experiência de descolonização e de justiça social, destacando-se experiências precoces de reforma agrária, de escolarização universal, de asilo político a refugiados e escravos foragidos - em que pese não haver abolido a escravidão de todo. Por isso tudo, Josefina Pla observa que El Supremo (como é chamado Francia):

\begin{abstract}
no es sólo un hombre; ni siquiera un hombre dueño de la totalidad del poder: es algo más, mucho más. Se declara consustanciado con su pueblo; lleva a cuestas el destino total; su ser y su hacer son una cosa misma con los de su pueblo. Su vida y la vida colectiva son más que inseparables: son una sola. Francia, alma del Paraguay cuerpo; o si se quiere, suma de almas del Paraguay en una. Más aún: asume la voluntad y la voz que ese pueblo no ha encontrado todavía (PLA, 2011, s/p).
\end{abstract}

Tendo tudo isso em mente, proponho a seguir a leitura de um capítulo (ou fragmento) de Yo el Supremo e da sua tradução por Antoine Berman. O capítulo que vamos analisar é crucial na história do Paraguai e da América Latina. Nos capítulos que antecedem a este, o governante paraguaio está reunido com os Belgrano e Echevarría, representantes da Junta das Províncias del Río de la Plata (que corresponderiam depois a Argentina e Uruguai), em uma data posterior à declaração da independência

\footnotetext{
${ }^{2}$ Do ponto de vista do gênero, como observou Josefina Pla (2011), Yo El Supremo é uma tríade: romance, história e biografia ao mesmo tempo.
} 
do Paraguai (1811), e, simultaneamente, alguns anos depois, com o representante diplomático do Império de Brasil, Antonio Manoel Correia da Câmara. O que está em jogo, em ambos os casos, é a longa luta pelo reconhecimento da independência paraguaia, mas também a desconfiança dos seus vizinhos da Plata e do Brasil quanto aos métodos do seu governo iluminista e antioligárquico, que punha em risco a estabilidade das oligarquias em toda a América Latina.

Nos capítulos/fragmentos que antecedem ao que vamos analisar, Francia recebe os representantes estrangeiros, e eles discutem enquanto saboreiam o mate servido por Francia, mas também participam de festividades e eventos sociais, o que permite a Francia conhecer melhor os seus "oponentes" no jogo diplomático. Nesse jogo, trata-se de decidir a questão das fronteiras do Paraguai, e também a insuportável política de taxação dos produtos paraguaios (erva-mate, tabaco) que são escoados pelos Rios Paraguai e Paraná. No encontro que tem com o representante diplomático do Império do Brasil, Francia não apenas analisa a revolução paraguaia, mas o modo como o Brasil se comporta no trato com o estrangeiro. Nesse sentido, o texto de Roa Bastos tem implicações políticas e éticas que de alguma forma tangenciam os problemas de tradução como "relação com o Outro", uma vez que a "leitura" que Francia faz de Correia da Câmara põe em cena ao mesmo tempo os entraves políticos e culturais do Brasil com o Paraguai. Trata-se também de uma análise mais ampla do jogo diplomático entre Brasil e Paraguai, que tem implicações tanto na Guerra da Tríplice Aliança (que chamamos de Guerra do Paraguai) quanto nos anos de ditadura militar, em ambos os países, do tempo em que o romance foi escrito.

\section{II - Yo el supremo e Moi, le Suprême: uma leitura anotada da tradução}

Para a leitura que se segue, usamos como obras de referência lexical as versões on-line do Diccionario de la Real Academia e do Trésor de la Langue Française. Em alguns casos foi necessário recorrer a léxicos particularizados, e a outras traduções do romance de Roa Bastos. Assim como as notas aqui têm caráter analítico, não se trata de apenas reproduzir os textos, mas de analisá-los em blocos divididos semanticamente de acordo com a linha de interpretação. Vale lembrar que a tradução de Berman não contém notas, 
mas o texto é antecedido por uma apresentação de duas páginas de Nicole Chardaire, que tenta situar o leitor com respeito a aspectos históricos e estilísticos.

Retomo a Correia da Cámara. En este mismo lugar, quince años más tarde estoy con el Manoel asistiendo a la representación, no de Tancredo, síno de Gasparina. Su autor, mi oficial de enlace Cantero, edecán del comisionado imperial que yo he puesto a su servicio, no tanto para que le sirva como para que me sirva, se ha ocupado de escribir la pieza y ponerla en escena. Ya no estamos ante el teatro de la tancredulidad sino de la incredulidad. ${ }^{3}$

Je reviens à Correia da Cámara. A ce même endroit, quinze ans plus tard, j'assiste avec Manoel à la représentation non de Tancrède, mais de Gasparina. Son auteur, mon officier de liaison Cantero, aide de camp de l'envoyé impérial, que j'ai mis à son service pour qu'il me serve, et non pour qu'il le serve, a écrit la pièce et l'a mise en scène. Nous ne sommes plus devant le théâtre de la tancredulité, mais devant celui de l'incrédulité. ${ }^{4}$

Gasparina es una mujer con gorro frigio que, según el autor, me representa a mí y a la República. No la encarna Petrona Zavala, sino una escultural muchacha payaguá que aparece en escena cubierta nada más que por las pestañas, los tatuajes y embijes $^{5}$ de todos colores que hacen de su cara una máscara.

Gasparina est une femme coiffée d'un Bonnet phrygien qui, d'après l'auteur, représente la République et moi. Elle n'est pas incarnée par Petrona Zavala,

\footnotetext{
3 A partir daqui, cito os textos de Roa Bastos e sua tradução iniciando pelas páginas 253 e 323, respectivamente. Uso os colchetes [ ] para marcar a mudança de página.

${ }^{4}$ Observe-se aqui o uso do neologismo, um modo de realizar a reativação vocabular como forma de enriquecimento da língua de chegada.

${ }^{5}$ A tradução por "peintures" empobrece a riqueza etimológica aqui, em nome de uma clarificação, mas logo abaixo os diversos nomes relacionados ao urucum, que têm acento regional, serão repostos. Aqui, a palavra "embije" vem de embijar, pintar; de bija, urucum.
} 


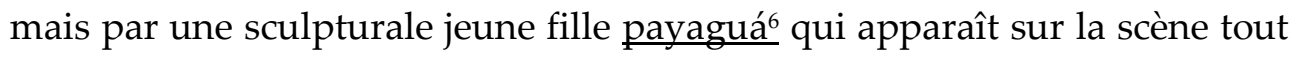
juste vêtue de ses cils, de ses tatouages et des peintures de toutes les couleurs qui transforment son visage en masque. ${ }^{7}$ //

Correia da Cámara se deshace en alabanzas a la obra. Sé que las hace a la actriz indígena. Alucinado por ella, no le saca los ojos de encima. Alucinado por ella, no le saca los ojos de encima. Sé que las hace a la actriz indígena. La devora por una mirada obscurecida por el brillo del deseo.La devora por una mirada obscurecida por el brillo del deseo. La República avanza hacia al centro del tablado para ser coronada por el Gran Hechicero ataviado de tricornio y levita. La Balanza en una mano, la Espada en la otra, la República se detiene bajo el solio de palmas contra en cual está erguido en dos patas un elegante león de utilería.

Correia da Cámara ne se lasse pas de faire l'éloge de la pièce. Je sais que ces éloges s'adressent en fait à l'actrice indigène. Fasciné, il ne la quitte pas des yeux. Il la dévore avec un regard obscurci par l'éclat du désir. La République s'avance vers le centre de la scène, pour être couronnée par le Grand Sorcier paré d'un tricorne et d'une lévite. La Balance dans la main, l'Épée dans l'autre, la République s'arrête sous le trône de palmes contre lequel se dresse un imposant lion de décor, les pattes en l'air.

La República gira lentamente con gran majestad hacia el gentío. Se afirma sobre la tijera de sus piernas. Las dos hojas ligeramente separadas. el pubis totalmente raspado. Cubierto de reflejos rotos, de claridades. Rayos fosforescentes de achiote, urukú, tapaculo y orellana, lo convierten en un sol negro. Lo mismo la boca. Dos faros de intermitente luz. Una mitad necesariamente negra, la otra necesariamente gris.

${ }^{6}$ Vale observar que Berman não usa notas de rodapé em nenhum momento, o que pode causar grande estranhamento no seu texto para o leitor francês, mas ao mesmo tempo mantém o fluxo necessário da leitura da prosa poética de Roa Bastos. O leitor logo saberá que se trata de uma nativa ameríndia.

${ }^{7}$ Enriquecimento qualitativo: preserva-se a relação paronomástica entre as palavras. 
La République, très lente et très majestueuse, se [323] tourne vers le public. Elle s'affirme sur les ciseaux de ses jambes. Les deux branches légèrement séparées. Couvert de reflets brisés, de clartés. Rayons phosphorescents de cocouyer ${ }^{8}$, de roukou, de tape-cul, d'orellana, qui font d'elle un soleil noir. Deux phares d'intermittente lumière. Une moitié nécessairement noire, l'autre nécessairement grise.

Correia se pasa la lengua por los labios. Pedante en sus expresiones, exclama: Esa Mujer-que-viene-de-los-bosques parece envuelta en una visibilidad deslumbrante, originaria. En ella lo visible y lo invisible son exactamente lo mismo. Nocturna a la vez que solar en cada uno de sus movimientos; hasta cuando finge la inmovilidad absoluta. Profundo secreto. Secreto inviolable.

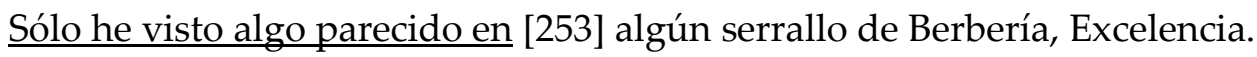

Correia se passe la langue sur les lèvres. Pédant dans toutes ses expressions, il s'exclame: Cette Femme-qui-vient-des-bois paraît enveloppée dans une visibilité aveuglante et primordiale ${ }^{9}$. En elle, le visible et l'invisible sont exactement identiques. Nocturne et solaire tout à la fois en chacun de ses mouvements, même lorsqu'elle feint l'immobilité absolue. Profond secret. Inviolable secret. Je n'ai vu des choses semblables ${ }^{10}$ que dans certains sérails de Barbarie, Excellence.

¡Esa mujer, Excelencia, es un meteorito desprendido de la protonoche ! ¡ Vea usted ! i i Vea usted ! i Se parte en dos ! ; Está inmóvil pero raya la noche, noche ! ¡ Se parte en dos! ¡ Son dos cuerpos y dos rostros en un solo cuerpo,

\footnotetext{
${ }^{8}$ É provável que seja um erro tipográfico, pois se trata do rocouyer, árvore cujo fruto é o rocou, que Berman grafa com a letra k, "rokou", talvez para guaranizar o francês._Segundo o TLF, os termos roucou e ouroucou são usados pelos viajantes e missionários no séc. XVI, e derivam do "tupi-guarani urucú, rucú, rocú". No guarani do Paraguay, a grafia é uruku. O termo achiote (de origem náuatl) é um equivalente de bija, que vem de bixa orellana, nome técnico da planta do urucum.

${ }^{9}$ Aqui talvez se possa dar razão aos argumentos de Charron, de um processo de "racionalização", que se dá não apenas em termos sintáticos (o uso da conjunção aditiva "et"), mas também em termos lexicais: "originaria" poderia se traduzir por originaire sem prejuízo.

${ }^{10}$ Aqui, ao invés de "racionalizar as estruturas sintáticas", Berman preserva a estrutura bífida que mescla o discurso narrativo e os diálogos, sem o uso de verbos dicendi ou sinais de pontuação.
} 
en un solo rostro ! El rústico autor, señor cónsul, ha pretendido representar en Gasparina a la Mujer-natural y también a la República. ; Pues lo ha conseguido, Excelencia, y en este mismo momento yo lo declaro más grande que el propio Racine ! El dialogo es idiota. Hay que aguantarlo.

Cette femme, Excellence, est un météorite échappé à la protonuit ${ }^{11}$ ! Voyez donc! Voyez! Elle se divise en deux! Elle est immobile, mais elle fend la nuit, la nuit! Elle se divise en deux ! Ce sont deux corps e et deux visages en un seul corps, en un seul visage ! Le rustique auteur, Monsieur le Consul, a prétendu représenter avec Gasparina la Femme-naturelle et aussi la République ! Il y est parvenu, Excellence, et en ce moment j' affirme qu'il est plus grand que Racine lui-même. Le dialogue est idiot ${ }^{12}$. Il faut le supporter.

El comisionado ha comprometido en nombre del Imperio enviar fusiles y cañones. ¡ El cargamento mais ${ }^{13}$ grande do mundo! Esto es lo que importa. No me importa gastar saliva con el emplumado cónsul carioca-riograndense. Nuestra saliva limpia y seca nuestras llagas mais mata a la serpiente, digo al macaco, remedándolo. Mientras Correia devora con los ojos a la Mujer-queviene-de-los-bosques, cimbrando desnuda bajo el gorro frigio; mientras el devoto de las musas gargantea frases atoradas, observo el extremo izquierdo de su boca;

L'envoyé s'est engagé au nom de l'Empire à nous envoyer des fusils et des canons. La cargaison mais grande do mundo ${ }^{14}$ ! C'est la seule chose qui compte. Peu importe de gâcher ma salive avec le consul emplumé carioca et

\footnotetext{
${ }^{11}$ Neologismo no original e na tradução.

12 Outra ruptura narrativa sutil, com a passagem do discurso direto à voz do narrador, e, ademais, a supressão do dêitico: o esperado seria ese diálogo, ce dialogue.

13 Aqui Roa Bastos começa a misturar o português e o castelhano, condizente com o modo como os brasileiros costumam falar castelhano usando termos cognatos. Neste caso, ademais, tratar-se-ia de um "erro" ("mais grande" no lugar de maior), mas é justamente esse erro que revela o caráter misturado da fala de Correia da Câmara.

14 Berman segue a ruptura roabastiana, mas aprofunda o estranhamento, na medida em que o leitor francês terá mais dificuldade de entender a proximidade entre as duas línguas misturadas.
} 
$\underline{\text { riograndais }}{ }^{15}$. Notre salive sèche et nettoie nos plaies, mais $^{16}$ tue le serpent, dis-je au macaque ${ }^{17}$ en le contrefaisant. Tandis que Correia dévore des yeux la Femme-qui-vient-des-bois, vibrante et nue sous son bonnet phrygien, tandis que l'ami des Muses gargouille des phrases étranglées, j'observe le bord gauche de sa bouche;

es esa comisura la que está en movimiento y pronuncia las palabras conocidas, mitad en español mitad en portugués. El resto de la boca se mantiene inmóvil y cerrado. Recursos de embusteros palaciegos, de enviados imperiales. Merced a largos años de ejercicio logran desdoblar sus labios y su lengua en porciones independientes. Articular al mismo tiempo frases entremezcladas con voces y entonaciones diversas. Ahora la mitad izquierda se arremanga el belfo del caballo descubriendo los dientes sin arrastrar en sus ondulaciones a la región derecha cerrada e impasible en las contrafrases. Conozco el truco. Yo mismo he aprendido a bifurcar la lengua. Fugar a la voz. Superponer las voces de ventriloquía a través de los labios completamente cerrados. Juego de niños para mí.

c'est cette commissure qui remue et prononce les paroles connues, la moitié en espagnol, l'autre moitié en portugais. Le [324] reste de la bouche est immobile et fermé. Recours de courtisans trompeurs, d'envoyés impériaux. Après de longues années d'exercices, il parviennent à dédoubler leurs lèvres et leurs langues en parties indépendantes. A articuler en même temps de phrases mêlées de voix et d'intonations diverses. A présent, la moitié gauche

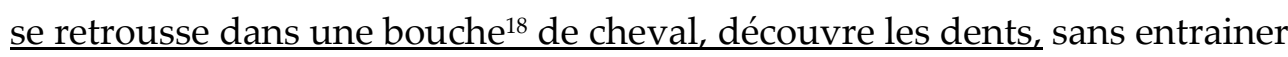

\footnotetext{
${ }^{15} \mathrm{O}$ uso do "et" parece ser racionalizante, mas ele se deve ao fato de que a anteposição do adjetivo "emplumé" seria um hipérbato mais visível; e manter dois adjetivos seguidos, um inteiro e um composto (emplumé carioca-riograndais) tornaria a frase pesada.

${ }^{16}$ A vírgula "racionaliza" a sintaxe estranha do original, que tem uma adversativa iniciada com uma conjunção em português ("mais", no lugar de "pero"); já o "mais" no francês é correto.

${ }^{17} \mathrm{O}$ termo "macaco" era usado pejorativamente para referir-se aos brasileiros, e foi empregado sobretudo durante a guerra da Tríplice Aliança, quando os jornais paraguaios representavam o Imperador como um macaco.

18 O dicionário da Real Academia define como "cada uno de los dos lábios del caballo y de otros animales." "Bouche" é certamente um empobrecimento qualitativo; também há uma racionalização no uso de vírgulas a seguir, mas ao mesmo tempo o fluxo das frases que se seguem criam uma "décalage" e uma "compensation" da perda realizada aqui.
} 
dans ses ondulations la région droite, impassible et fermée dans les contrephrases. Je connais bien le truc. J'ai moi-même appris à bifurquer la langue. A faire fuguer la voix ${ }^{19}$. A superposer les voix ventriloques à travers des lèvres complètement fermés. Un jeu d'enfant, pour moi.

El arte que este mamarracho imperial no domina. Pretende convencerme de que el imperio ofrece su alianza al Paraguay sólo para protegerlo de las acechanzas de Buenos Aires. Conoce mis mataduras; yo, las del imperio. Lo que éste busca es justamente lo contrario: apoderarse de la Banda Oriental, aplastar al Plata. Tragar-se por fin a su "aliado". Poca cosa. Nada de nada. Dejo que el comisionado boquee a su gusto. El que tiene el anzuelo soy yo. Aflojo el hilo al dorado pez del imperio. Entretanto me hago entregar copia de toda correspondencia secreta con los espías ingleses y franceses. Entonces pego el tirón. Traigo a las riberas mis [254] exigencias al emisario, y no lo suelto hasta que me asegura que mis reclamaciones serán satisfechas: Reconocimiento pleno, irrevocable, de la Independencia del Paraguay. Devolución de territorios y ciudades usurpados. Indemnización por las invasiones de las bandeiras. Nuevo tratado de límites que borre las cruciferarias fronteras impuesta por la bula del papa Borgia y por el tratado de Tordesillas. Trueque de armas y municiones por madera y yerba.//

Art que le polichinelle ${ }^{20}$ impérial ne domine point. Il prétend me convaincre que l'Empire n'offre son alliance au Paraguay que pour le protéger des embûches de Buenos Aires. Il sait là où le bât me blesse; je sais où le bât $\underline{\text { blesse }^{21}}$. Ce que cherche l'Empire, c'est justement au contraire : s'emparer de

\footnotetext{
${ }^{19}$ Aqui a sintaxe paratática é respeitada. Trata-se de um momento chave no livro, a ideia de "bifurcação" da língua diplomática (um dizer "slant", de viés, como diria Dickinson). Essa ideia de bifurcação e de ventriloquismo, que aparece ao longo do livro, também aponta para o interesse de Berman no livro: a "parlance" de Yo El Supremo é ao mesmo tempo coloquial e erudita, nacional e estrangeira, original e "traduzida". Nesse sentido, o romance de Roa Bastos já adianta muitos dos temas da teoria bermaniana. ${ }^{20}$ Aqui se vê uma interessantíssima "décalage" cultural. "Mamarracho" é uma "persona estrafalaria o ridícula", segundo o Real Academia, e esse dicionário aponta que a provém do árabe "muharrig, bufón". Ora, como se sabe "Polichinelle" é um personagem da comédia italiana, mas a palavra é usada no francês para designar uma pessoa ridícula.

${ }^{21}$ Este é um momento decisivo para entender o jogo diplomático, e a tradução: representando o Império, Câmara finge amizade com Francia (Paraguai), mas quer antes usar a aproximação com o Paraguai para apoderar-se da Banda Oriental (futuramente Uruguai) e assumir o comando estratégico do Cone Sul - e
} 
la Rive orientale, écraser le Río de la Plata. Avaler finalement son «allié ». Peu de chose. Vraiment rien. Je laisse l'envoyé béer la bouche à son gré. C'est moi qui possède l'hameçon. Le laisse couler le fil pour le poisson doré de l'Empire. Entre-temps, je me fais remettre la copie de toute sa correspondance secrète avec les espions français ou anglais ${ }^{22}$. Ensuite je ferre et je tire un bon coup. Je traîne l'émissaire au rive de mes exigences, et je ne le lâche plus jusqu'à ce qu'il m'assure que toutes mes réclamations seront satisfaites: Reconnaissance pleine et irrévocable de l'indépendance du Paraguay. Restitution des territoires et des villes usurpés. Indemnisation pour les raids des bandeiras 23. Nouveau traité frontalier qui efface les frontières portecroix ${ }^{24}$ imposées par la bulle du pape Borgia et par le traité de Tordesillas. Des armes et des munitions en échange de bois et de maté.//

Vea, señor cónsul, usted va a ponerme por escrito todo lo que ha prometido. Tomo sus palabras como salidas de la misma boca de su emperador. Va en ellas el honor del imperio. Eh eh ah. ¡Mais claro, absolutamente verdade, Excelencia! ; Vocé va a tener el cargamento de armas mais grande do mundo! Que venga pronto el armamento, le digo, remedándolo: Que ${ }^{25}$ sabe faz a hora nao espera acontecer. ${ }^{26}$ Os amores na mente as flores no chao/A certeza na frente/A historia na mao. ${ }^{27}$ ¿E? ¿Eh? ¡Certissimamente Excelencia!

\footnotetext{
de toda a América do Sul. Nesse momento crucial, o jogo verbal do discurso de Francia se dá em termos "vernaculaires", ou seja, em linguagem coloquial. Mais do que as palavras, a ideia (a imagem, diríamos), a ser traduzida é que o Império pretende literalmente "montar sobre" Francia/Paraguai como se ele fosse o cavalo para o combate a Buenos Aires. "Matadura" é a ferida no cavalo causada por uma sela inferior ou defeituosa, e a expressão "darle a alguien en las mataduras" significa ferir alguém com aquilo que ele mais despreza. O termo francês "bât" também é uma sela inferior (usada para burros, geralmente), e daí deriva a expressão "chacun sait ou le bât le blesse", literalmente, cada qual sabe onde a sela machuca. Apesar de suprimir "império", Berman preserva a imagem e o sentido, e sobretudo a linguagem coloquial, o provérbio.

${ }^{22}$ Teria a inversão dos termos (primeiro o francês) uma significação? Talvez para Berman o leitor francês se sinta mais "afetado" por se ver em situação constrangedora de colaborador do movimento anti-Francia e anti-Paraguai.

${ }^{23}$ Como sempre, nenhuma nota para conduzir o leitor à complexa relação entre as "entradas e bandeiras" (que hoje são como as grilagens incentivadas por Bolsonaro) e a política externa dos países do cone sul. Além disso, o estranhamento maior é causado pelo uso do termo em português.

${ }^{24}$ A eliminação do hífen em "portecroix" parece remeter à origem galega do original "cruciferarias".

${ }^{25}$ Conforme o original.

${ }^{26}$ Aqui e em outros lugares, a transcrição de Roa Bastos da canção (ver nota seguinte) destoa do original. ${ }^{27}$ Para o leitor brasileiro, a citação anacrônica da canção de protesto de Geraldo Vandré ("Para não dizer que não falei das flores", 1968) deixa mais clara a estrutura temporal bífida do romance de Roa Bastos
} 
Certissimamente! ¿Cuándo vendrá el cargamento, seor consuleiro 28 ? Embora embora, que esperar nao é saber, le zumbo en la oreja. ¡Certissimamente!, fugó la voz del cónsul de izquierda a derecha. Movimiento de succión con el doble émbolo de la linguageral.

Voyez-vous, Monsieur le Consul, vous allez me coucher par écrit tout ce que vous m'avez promis. Je considère que vos paroles sortent de la bouche même [325] de votre empereur. J'y vois l'honneur de l'Empire. Hé hé ! Ah ! Mais bien sûr, bien sûr, Excellence! Vocé vai avoir la cargaison d'armes mais grande do mundo! Que espera faz a hora nao espera acontecer. Os amores na mente as flores no chao / A certeza na frente / A historia na mao. Hein ! Mais très certainement, Excellence! Très certainement, Excellence! Quand viendra la cargaison, seor consuleiro ? Embora, embora, que esperar nao é saber, je lui bourdonne à l'oreille. Mais très certainement! fait la voix du consul en fuyant de gauche à droite. Mouvement de succion avec le double piston de la linguageral ${ }^{29}$.

Está además la cuestión de esos limites a la bailanta ${ }^{30}$ de lo que tenemos que ajustar, eh seor cónsul. Los saltos de agua. Las presas. ¡ Sobre todo las presas que quieren convertirnos en una presa ao gosto do Imperio mais grande do mundo! Eh. Eh. Eh. ¡Ah! ¡Ah! ¡Ah! ¡Certissimamente!, seguía mascullando el incierto embustero por una y otra juntura. Ah y ah y ah, no vuelva a omitir el tratamiento adecuado a la República y al Gobierno Supremo. Vea que esto

(que está falando de Francia e das ditaduras militares latino-americanas ao mesmo tempo, inclusive da ditadura brasileira). E o fato de que essa citação venha da boca de Francia (para Correia Câmara) também deixa mais clara a ironia de Francia/Roa Bastos em relação ao Brasil (e ao seu representante). Para o leitor francês, Berman simplesmente espera que ele saiba disso (ou se interesse em pesquisar), ou simplesmente passe por um estranhamento total. Acredito que, ao não anotar sua tradução, Berman segue essa dupla orientação. Vale destacar ainda que as omissões de marcadores gráfico-fonéticos como o acento agudo, $\mathrm{o}$ til e a cedilha já estão presentes no original.

${ }^{28}$ Essa palavra parece mais um neologismo irônico (cônsul + brasil + -eiro, sufixo de matiz pejorativo neste caso, como em carniceiro ou justiceiro).

${ }^{29}$ Outro neologismo (pela grafia) importante: chamava-se língua geral a língua tupi-guarani crioula, e que servia para se comunicar com as várias etnias do tronco tupi-guarani do Brasil, usada sobretudo pelos primeiros bandeirantes. Dessa língua derivam muitos dos nomes de cidades e rios, como Anhangabaú. Essa visão mecânica ("double piston") da língua diplomática numa língua artificial (o ñeengatu jesuítico) também aponta para o caráter estrangeirizante da tradução - e da traição, nesse caso.

${ }^{30}$ O Real Academia define: "Arg. Fiesta de Pueblo em la que se baila.". 
no es teatro, lo que convengamos con el imperio no será materia de aplausos sino de firmas muy firmes. Francas y honradas. De una cordillera a la otra.

Il y a en autre la question de ces frontières mouvantes que nous devons corriger, hein, seor consul! Les cataractes. Les barrages. Surtout ces barrages qui veulent nous rembarrer ${ }^{31}$ ao gosto do Imperio mais grande do mundo! Hé hé ! Ah! ah! Mais très certainement, continue a marmotter l'incertain menteur par ses deux jointures. Ah ! ah ! et ah ! Tâchez de ne plus oublier de traiter correctement la République et le gouvernement Suprême. Voyezvous, il ne s'agit pas de théâtre. Ce dont nous allons convenir ensemble ne sera point matière à applaudissements, mais à très fermes signatures. Franches. Honorées. D'une cordillère à l'autre.

¡Certissimamente Excelencia! Cuando vi que la comisura-comisionaria iba a deslizarme algo al oído, levanté la mano: Vocé va a pedirme que después de la función le envíe a su alojamiento a la Mujer-que-viene-de-los-bosques, ¿no? Usted pretende que le repita en privado la escena de la tijera ¿no es eso, seor conselheiro? ; Usted es un genio, Señor Dictador Perpetuo de la República do Paraguay! ¡ Tiene dotes de Taumaturgo adivinador! ¡ El más $\underline{\text { zahorí32 }}^{2}$ de los adivinadores! ¡ Telepatía pura! Vea, mi estimado telépato Correia, usted comprendrá que no puedo prostituir a la República arrimándola a su cámara. No, da Cámara, esta correia no és para su cuero. Puedo yo pedirle a usted que traiga [255] al imperio y lo meta en mi cama?

Mais très certainement, Excellence ! Quand je m'aperçus que la commissurecommissionnaire allait me glisser quelque chose à l'oreille, je levai la main : vous allez me demander qu'après la représentation j'envoie à votre logement

\footnotetext{
31 Trata-se aqui de um enriquecimento qualitativo capaz de recriar, por "décalage", um jogo verbal intraduzível entre "presas" (represas) e "presas" (presa, no sentido de caça). Aqui o jogo fica entre "barrage" (barragem, represa) e "rembarrer", mandar de volta para o seu lugar - pois os brasileiros querem enxotar os paraguaios do território que eles pretendem dominar, e que dominarão depois da Guerra da Tríplice Aliança.

32 Persona a quien se atribuye la facultad de descubrir lo que está oculto, especialmente manantiales subterrâneos ("ár. zuhari, geomancia, der. de azzuharah, Venus, a cuyo influjo atribuían alguns de essa arte" - Real Academia)
} 
la Femme-qui-vient-des-bois, n'est pas, seor conselheiro? Vous êtes un génie, Monsieur le Dictateur Suprême de la République du Paraguay! Vous avez de dons de thaumaturge, de devin! Le plus $\underline{\text { sorcier }^{33}}$ des devins! Télépathie pure! Voyez-vous, mon cher télépate Correia, vous comprenez que je ne puisse prostituer la République en la mettant dans votre lit. Non, Correia, vous ne caracolerez point avec ce joli caraco $^{34}$. Pourrais-je vous demander, moi, de m'amener l'Empire et de le mettre dans mon lit ? [326]

Francamente no. Lo menos que se puede decir sobre eso, seor consuleiro, es que no está bien, ¿no? ¡Nada beim! Os amores na mente / As flores no chao ¿eh, no? ¡Certissimamente tein razón, Excelencia! Bien entonces mañana seguimos conversando en la Casa de Gobierno, que agora la función se ha terminado. Veo entrar al ministro Benítez con el sombrero de plumas del enviado imperial. ¿No sabe usted, bribón, que no debe aceptar regalos de nadie? i Devuelva inmediatamente ese adefesio con el que se le ha pretendido sobornar! Por este despropósito le impongo un mes de arresto.

Franchement non. Le moins qu' on puisse dire à ce sujet, seor consuleiro, c'est que ne serait pas bien, non? Os amores na frente / As flores no chao, non? Tein $^{35}$ raison absolument, Excellence! Eh bien, nous continuerons à converser demain au palais du gouvernement, puisque la représentation ${ }^{36}$ est terminée. Je vois entrer le ministre Benítez avec le chapeau à plume de l'envoyé impérial sur la tête. Ignorez-vous, faquin, qu'il ne faut accepter de cadeaux de personne ? Rendez immédiatement cet épouvantail à moineaux

\footnotetext{
33 "Sorcier" empobrece etimologicamente o termo "zahorí". Chamán seria uma boa opção.

${ }^{34} \mathrm{O}$ jogo onomástico-homográfico entre Correia e correia, que reverbera semanticamente em "cuero", mostra o caráter inventivo e poético de Yo El Supremo. Berman não deixa por menos, e vai além do jogo homofônico/paronomástico: além de ser termo de equitação (fazer meias-voltas com o cavalo), caracoler também tem sentido erótico (= trepar); caraco é um corpete do vestuário feminino, um termo de etimologia confusa, podendo ser inclusive de origem ameríndia!. Na tradução de Helen Lane, lê-se: "No, da Cámara, that lovely naked body will not touch your raw hide". (ROA BASTOS, 2018: 296)

${ }^{35}$ Assim como Roa Bastos forja um português misturado (como o guarani jehe'a, misturado ao espanhol), usando palavras como "beim" "seor" e até mesmo "Que" no lugar de "Quem", Berman cria aqui um jehe'a galo-portugês: "tein". As formas de mistura do guarani ao espanhol (jopara e jehe'a) constituem um dos traços distintivos da fala paraguaia e fronteiriça explorada por Roa Bastos.

${ }^{36}$ Fechando em clave de ouro, Berman mantém o sentido estético (teatro) e político (diplomático) do termo "función" com represéntation, preservando o caráter bífido da fala de Francia, e, consequentemente, a "parlance" (falância) do romance latino-americano.
} 
avec lequel on a voulu vous suborner! Pour cette gaffe, vous me ferez un mois d'arrêt.

\section{Referências bibliográficas}

ANDRADE, Oswald de. A utopia antropofágica. Prefácio de Benedito Nunes. São Paulo: Globo/Secretaria do Estado de Cultura de São Paulo, 1990.

BERMAN, Antoine. L'Épreuve de l'étranger. Culture et traduction dans l'Allemagne romantique. Paris: Gallimard, 1984.

BERMAN, Antoine. La traduction et la lettre ou l'auberge du lointain. In: BERMAN, A. et al. Les tours de Babel. Mauvezin: Trans-Europ-Repress, 1985, p. 35-150.

BERMAN, Antoine. La traduction des œuvres latino-américaines. Lendemains, Koln, n. 27, p. 39-44, 1982.

BERMAN, Antoine. La voix des sans-voix - Arguedas, Garcia-Marquez, Scorza, Roa-Bastos. Canal - Dossier: Histoire \& Fiction dans la litterature d'Amerique Latine, Paris, n. 39, p. 4-5, 1980.

BERMAN, Antoine. Pour une critique des traductions: John Donne. Paris: Gallimard, 1995.

BERMAN, Antoine. Maté et communication. Esprit (nouvelle série), n. 452. Paris: Seuil, p. 809- 815, 1975.

BERMAN, Antoine; GARMA, Isabelle. Trente ans de luttes nationales. Esprit (nouvelle série), n. 456. Paris: Seuil, p. 1240-1251, 1976.

CHARRON, M. Berman, étranger à lui-même? TTR, 14 (2), p. 97-121, 2001. Disponível em: https://doi.org/10.7202/000571ar

GODARD, Barbara. L'Éthique du traduire : Antoine Berman et le « virage éthique» en traduction. TTR, 14 (2), p. 49-82, 2001. Disponível em: https://doi.org/10.7202/000569ar 
PETRY, Simone Christina. A tradução como obra: relações entre a leitura bermaniana do conceito romântico de obra de arte e sua reflexão sobre tradução. 2016. 186p. Tese (Doutorado em Teoria e História Literária) Instituto de Estudos da Linguagem, Unicamp, Campinas, São Paulo, 2016.

PLA, Josefina. Yo El Supremo, de Roa Bastos. In: SAMUDIO, José F. Comentarios sobre Yo El Supremo. 2a ${ }^{a}$. Edición. Assunción: Club del Libro n. 1, 2011. Disponível em http://www.portalguarani.com/2347 jose federico samudio falcon/17010 comentarios sobre yo el supremo edicion al cuidado jose federico sa mudio.html

ROA BASTOS, Augusto. I, the Supreme. Translated by Helen Lane. New York: Vintage Books, 2018.

ROA BASTOS, Augusto. Moi, le Suprême. Traduit de l'espagnol paraguayen par Antoine Berman. Paris: Belfond, 1977 (Le livre de Poche).

ROA BASTOS, Augusto. Yo el Supremo. Buenos Aires: Sudamericana, 1990.

SPIVAK, Gayatri C. The Politics of Translation. In: Outside in the Teaching Machine. New York: Routledge, 1993, p. 179-200.

VENUTI, Lawrence. The Scandals of Translation: Towards an Ethics of Difference. New York, Routledge, 1998.

\section{Resumo}

A tradução de Antoine Berman de Yo el Supremo, de Roa Bastos, foi publicada em 1977, três anos depois do original, e realizada provavelmente quando Berman ainda estava na Argentina desenvolvendo uma leitura crítica do romance latino-americano do Boom, e das suas conexões com a História, marcada pelo peronismo e pelas ditaduras militares. Neste artigo queremos assinalar - na linha desenvolvida por Simone Petry- que não apenas a reflexão crítica de Berman desse período antecede e alimenta a sua posterior teoria ética do traduzir, mas também que a sua prática de tradutor aponta para a ideia de convívio com o estrangeiro que já é uma ética da diferença, sem deixar de ser uma estética da invenção. Para tanto, além de considerações teóricas, propomos a leitura face a face de um capítulo chave 
de Yo el Supremo e Moi, le Suprême, no qual a diplomacia e a tradução se entrelaçam.

Palavras-chave: Roa Bastos; Yo El Supremo; Antoine Berman; Tradução; Ética; Diplomacia.

\begin{abstract}
La traducción de Antoine Berman de Yo el Supremo de Roa Bastos se publicó en 1977, tres años después del original, y se llevó a cabo probablemente cuando Berman aún estaba en Argentina desarrollando una lectura crítica de la novela latinoamericana del Boom, y de sus conexiones con la historia, marcada por el peronismo y las dictaduras militares. En este artículo queremos señalar - en la misma línea desentrañada por Simone Petry - que no solo la reflexión crítica de Berman de esa época precede y alimenta su posterior teoría ética de la traducción, sino que su práctica traductora remite a la idea de convivencia con el extranjero que es ya una ética de la diferencia, sin dejar de ser una estética de la invención. Para ello, además de las consideraciones teóricas, proponemos una lectura confrontada de un capítulo clave de Yo el Supremo y Moi, le Suprême en el que se entrecruzan diplomacia y traducción.

Palavras-clave: Roa Bastos; Yo El Supremo; Antoine Berman; Tradução; Ética; Diplomacia.
\end{abstract}

